\title{
Effect of Magnetic Field on the Steady Nanofluid Flow Past Obstacle
}

\author{
University of Blida, Fundamental and Applied Physics Laboratory, Algeria, khliliyacine1@ gmail.com
}

\begin{abstract}
The fluid flow and heat transfer of a nanofluid past a circular cylinder in a rectangular duct under a strong transverse magnetic field is studied numerically using a quasi two-dimensional model. Transition from laminar flow with separation to creeping laminar flow is determined as a function of Hartmann number and the volume fraction of nanoparticle, as are critical Hartmann number, and the heat transfer from the heated wall to the fluid. Mixing downstream cross-stream which is induced by the cylinder wake was found to increase heat transfer. The successive changes in the flow pattern are studied as a function of the Hartmann number. Suppression of vortex shedding occurs as the Hartmann number increases.
\end{abstract}

Keywords: nanofluid; magnetohydrodynamics; volume fraction; Hartmann number.

Received 24June 2021; Accepted 25August 2021.

\section{Introduction}

It is known that traditional heat transfer fluids (water, air, oil, etc.) have inherently low thermal conductivity. In order to improve the performance of heat transfer fluids, dispersion of nanosized particles into the base fluids has become a promising approach. It has been indicated in several studies that the cooling performance and compactness of engineering devices and equipment improved a lot with the use of nanofluid as a heat transfer fluid.

Nanofluid selection is based on nanofluid properties, sizes, shapes, volume fractions and stabilities of the nanoparticles as well as thermophysical properties of nanofluids which play important roles on the heat transfer performances. Generally in nanofluid convective heat transfer modeling, the nanofluid simulations can be considered into two categories; the single-phase modeling which is the combination of nanoparticle and base fluid which is considered as a single-phase mixture with steady properties (mixed properties between the nanoparticle and base fluid properties) and the two phase modeling which the nanoparticle properties and behaviors are considered separately from the base fluid properties and behaviors. Some recent reviews on the subject have thoroughly discussed the unique heat transfer properties and thermal conductivity enhancement of nanofluids and highlighted the use of these fluids in heat transfer application.

R.D. Selvakumar et al. [1] discussed the effects of uncertainties in effective properties of nanofluids on flow and heat transfer characteristics during an unconfined forced convective flow around a circular cylinder. Selvakumarand Dhinakaran [2] investigated with Eulerian-Lagrangian modelling approach the flow field, heat transfer and particle distribution in nanofluid flow in a parallel-plate microchannel, with a focus on relatively low Reynolds numbers. Najiyah Safwa Khashi'ie [3], presented the scrutinized the laminar and two-dimensional $\mathrm{Al}_{2} \mathrm{O}_{3}-\mathrm{Cu}$ /water nanofluid flow and heat transfer towards a permeable stretching/shrinking cylinder with prescribed surface heat flux. A similar study on forced convective heat transfer past a square cylinder by Valipour et al. [4] also confirmed their observations on circular cylinder. A numerical study on forced convective nanofluid flow around a circular cylinder by Vegad et al. [5] in which the effective properties were calculated using Maxwell Garnett model [6] also showed synonymous results. M. Sheikholeslami et al. [7] in their review presents empirical and numerical analyses of thermal performance development in flat plate solar collectors [8] performed a 
numerical study on upward laminar mixed convective flow around a circular cylinder and showed that nanofluids with smaller nanoparticles produced higher heat transfer rates. Farooji et al. [9] numerically simulated a laminar nanofluid flow around a circular cylinder and exhibited that there is an optimum particle volume fraction for a given nanoparticle diameter at which the maximum heat transfer will be observed. A numerical analysis of transient natural convective boundary layer flow past a vertical cylinder using nanofluids by Chamkha et al. [10] showcased the dependence of heat transfer enhancement on nanoparticle shape. It was noted that spherical particles are capable of producing higher heat transfer rates. Notable aspect of this work is that, Brownian motion and thermophoresis were considered while determining the effective thermal conductivity of nanofluids. Sarkar et al. [11] made a detailed study on the effect of Aluminum oxide suspended in water at concentration of $0.03 \%$ as nanomaterial for turbulent flow using multiple twisted tapes $\left(\mathrm{TT}_{\mathrm{n}}\right)$ in a solar flat plate collector was scrutinized. [12] a buoyancy driven mixed convective flow around square cylinder using nanofluids by Sarkar et al. [13] showed that heat transfer is a function of particle volume fraction. Addition of nanoparticles to the base fluid resulted in more number of low frequency higher energy modes in a mixed convection flow around a square cylinder [14]. During a mixed convective vertical flow and heat transfer around a square cylinder using nanofluids, addition of nanoparticles to the base fluid caused a decrease in total entropy generation [15].

Apart from the tremendous engineering importance, the MHD flow and heat transfer problems are fundamentally very interesting as well as challenging, since the addition of Maxwell's laws to ordinary hydrodynamics and the associated action of the Lorentz forces and Joule heating give rise to intriguing physical phenomena. In the context of using heat transfer promoters like cylindrical obstacles to induce vortices and enhance heat transfer rates, experimental studies are performed by several researchers [16-17]. During the recent years, many researchers have studied the effect of a magnetic field on flow and heat transfer [18-20]. For example, Yoon et al. [21] presented the results of a numerical study on the flow pattern and heat transfer characteristic around a circular cylinder in the presence of a magnetic field. Grigoriadis et al. [22] studied the steady and unsteady MHD flow past a circular cylinder utilizing the immersed boundary method. Chatterjee [23] also reported numerical studies for the wall bounded MHD flow and heat transfer around a circular obstacle for low Reynolds and Hartmann numbers. They demonstrated that the hydrodynamic instability was suppressed more for transverse magnetic field in comparison to the streamwise magnetic field. Hussam et al. [24] also studied numerically fluid flow and heat transfer in a MHD flow past a circular cylinder in a duct at high Hartmann number. Chatterjee D. et al. [25] they use electromagnetic fields to control the flow separation during the flow of electrically conducting fluids around bluff obstacles.

Due to the outstanding potential of nanofluids in enhancing heat transfer many researchers have studied their effects and characteristics, but most of these studies are oriented toward simple geometries. However, the main motivation of this study is to predict the effects of nanoparticles on heat transfer past a circular cylinder, the fluid flow parameters such as recirculation length, pressure coefficient etc. are investigated as side-effects.

\section{Problem Statement and Mathematical Formulation}

The problem under consideration is schematically shown in Fig. 1.We consider the flow of an incompressible Newtonian fluid past a smooth, infinitely long, straight, circular cylinder in an unbounded fluid domain in which the streamwise direction is perpendicular to the cylinder axis. The upstream and downstream lengths of the computational domain are fixed as $L_{u}=12 \mathrm{D}$ and $L_{d}$ $=42 D$, respectively. These values are chosen to in order to reduce the effect of outlet and inlet boundary conditions on the flow patterns in the vicinity of the obstacle. The blockage ratio $=D / H=0.05$ (where $H$ is the width of the computational domain). An external magnetic field of amplitude $B_{0}$ is applied along the transverse direction $y$.

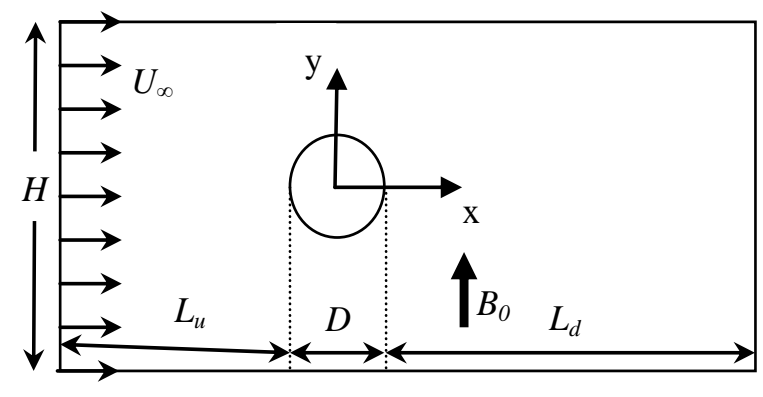

Fig. 1. Schematics of the unconfined flow arounda circular cylinder.

\subsection{Governing equations}

The governing equations for two dimensional and steady state flow with single phase approach for nanofluid modeling is mass conservation, momentum, and energy equations, as:

$$
\begin{gathered}
\nabla . \mathrm{v}=0 \\
\rho_{n f}(\mathrm{v} . \nabla) \mathrm{v}=-\nabla \mathrm{P}+\mu_{n f} \nabla^{2} \mathrm{v}+F_{L} \\
(\mathrm{v} . \nabla) T=k_{n f} \Delta T
\end{gathered}
$$

Where $\mathrm{v}$ is the velocity field, $\mathrm{p}$ the dynamic pressure, $\mathrm{j}$ the current density, $F_{L}=N\left(\mathbf{j} \times B_{0}\right)$ is the Lorentz force with $N=H a^{2} / R e$

In the present study the following dimensionless parameters are introduced to obtain the governing equation (1-3) in non-dimensional forms as follows:

$$
\begin{gathered}
X=\frac{x}{D} ; Y=\frac{y}{D} ; U=\frac{u D}{\alpha_{f}} ; V=\frac{\mathrm{v} D}{\alpha_{f}} ; \\
\Theta=\frac{\left(T-T_{\infty}\right)}{\left(T_{C}-T_{\infty}\right)} ; P=\frac{\mathrm{P} D}{\rho_{n f} \propto_{f}^{2}}
\end{gathered}
$$

The non-dimensional formulation of the MHD 
equations within the inductionless approximation is:

$$
\nabla \cdot V=0
$$

$$
\begin{gathered}
(V . \nabla) V=-\frac{\rho_{\mathrm{f}}}{\rho_{\mathrm{nf}}} \nabla P+\frac{\mu_{\mathrm{nf}}}{v_{f} \rho_{\mathrm{nf}}} \frac{1}{R e} \nabla^{2} V-\frac{\sigma_{n f} \rho_{f}}{\sigma_{f} \rho_{n f}} H a^{2} . \operatorname{Pr} . V, \\
(V . \nabla) \Theta=\frac{a_{n f}}{a_{f}} \frac{1}{\operatorname{RePr}}\left(\nabla^{2} \Theta\right), \\
\nabla . \boldsymbol{j}=0,
\end{gathered}
$$

here,$j=\mathbf{j} / \sigma u_{\infty} B_{0}$ is the expression of the dimensionless density of induced electric current, given by:

$$
\boldsymbol{j}=E+U \times B_{0}
$$

In this case, $\mathrm{E}=0$, represents the electric field, so Ohm's law reduces to:

$$
\boldsymbol{j}=U \times B_{0}
$$

In Eq. (5), $H a=B_{0} D \sqrt{\sigma_{f} / \rho_{f} v_{f}}$ is the Hartmann number.

$$
\frac{k_{n f}}{\mathrm{k}_{\mathrm{f}}}=1+64.7 \varphi^{0.7460}\left(\frac{d_{f}}{d_{p}}\right)^{0.3690}\left(\frac{k_{p}}{k_{f}}\right)^{0.7476} \times \operatorname{Pr}^{0.9955} \operatorname{Re}^{1.2321}
$$

For the dynamic viscosity of the nanofluid, the equation:

$$
\begin{gathered}
\mu_{n f}=\frac{\mu_{f}}{\left(1-34.87\left(d_{p} / d_{f}\right)^{-0.3} \times \varphi^{1.03}\right)} \\
d_{f}=\left(\frac{6 M}{N \pi \rho_{f 0}}\right)^{1 / 3}
\end{gathered}
$$

\begin{tabular}{|c|c|c|c|c|}
\hline & $\begin{array}{c}k \\
{\left[\mathrm{~W} \cdot \mathrm{m}^{-}\right.} \\
\left.{ }^{1} \cdot \mathrm{K}^{-1}\right]\end{array}$ & $\begin{array}{c}\rho \\
{\left[\mathrm{Kg} \cdot \mathrm{m}^{-3}\right]}\end{array}$ & $\begin{array}{c}\mu 10^{-3} \\
{\left[\mathrm{Kg} . \mathrm{m}^{-}\right.} \\
\left.{ }^{1} \cdot \mathrm{s}^{-1}\right]\end{array}$ & $\begin{array}{c}C_{p} \\
{\left[\mathrm{~J} \cdot \mathrm{kg}^{-}\right.} \\
\left.{ }^{1} \cdot \mathrm{K}^{-1}\right]\end{array}$ \\
\hline Water & 0.613 & 997.1 & 1.002 & 4179 \\
\hline $\mathrm{Cu}$ & 400 & 8954.0 & ---- & 383.0 \\
\hline
\end{tabular}

With: $d_{p}$ : is the mean diameter of the nanoparticles; $d_{f}$ : is equivalent diameter of a base fluid molecule; $M$ : the molecular weight; $N$ : the Avogadro number $=6.022910^{23}$ $\mathrm{mol}^{-1}$; and $\rho_{f 0}$ : the density of the base fluid at $\mathrm{T}=293{ }^{\circ} \mathrm{K}$.

Table 1

Thermo-physical properties of the base fluid and

\section{Numerical implementation}

The commercial CFD code ANSYS FLUENT 15 was employed to perform this study. The conservation equations subjected to the aforementioned boundary conditions are solved using a finite volume based numerical method. An implicit scheme is applied to obtain the discredited system of equations. The quadratic
The boundary conditions are as follows: at the inlet, ( $U=1 ; V=0 ; \Theta=0)$; at the outlet: Outflow boundary condition $(\partial U / \partial X=\partial U / \partial X=\partial \theta / \partial X=0)$ is proposed and at cylinder wall boundary $(U=V=0$ "and» $\Theta=1) \ldots$

\subsection{Thermal properties of nanofluids}

The change in physical parameters, due to the addition of nanoparticles in the base fluid, is taken into account.In this work we use:

For the density of the nanofluid the equation:

$$
\rho_{\mathrm{nf}}=(1-\varphi) \rho_{\mathrm{f}}+\varphi \rho_{\mathrm{p}}
$$

For specific heat of the nanofluid the equation:

$$
\left(\rho C_{p}\right)_{n f}=(1-\varphi)\left(\rho C_{p}\right)_{f}+\varphi\left(\rho C_{p}\right)_{p}
$$

Where, $\varphi$ is the volume fraction of nanoparticle: $\varphi=\frac{\text { Volume of nanoparticles }}{\text { Total volume of solution }}$.

For the thermal conductivity of the nanofluid, the equation: upstream interpolation convective kinetics (QUICK) scheme is used for spatial discretization of the convective terms and a central difference scheme is used for the diffusive terms of the momentum and energy equations. The SIMPLE (semi-implicit method for pressure linked equations) algorithm is used as the pressure-velocity coupling scheme. Finally, the algebraic equations are solved by using the Gauss-Siedel point-by-point iterative method in conjunction with the Algebraic Multigrid (AMG) method solver.

\subsection{Grid génération}

A study was carried out on three meshes: (M1) 56.900 quadrilateral elements, 57.490 nodes; (M2) 93.000 quadrilateral elements, 93.570 nodes; and (M3) 128.800 quadrilateral elements, 129,640 nodes, to ensure that the solution is independent of the mesh. A refinement of the elements around the cylinder has been

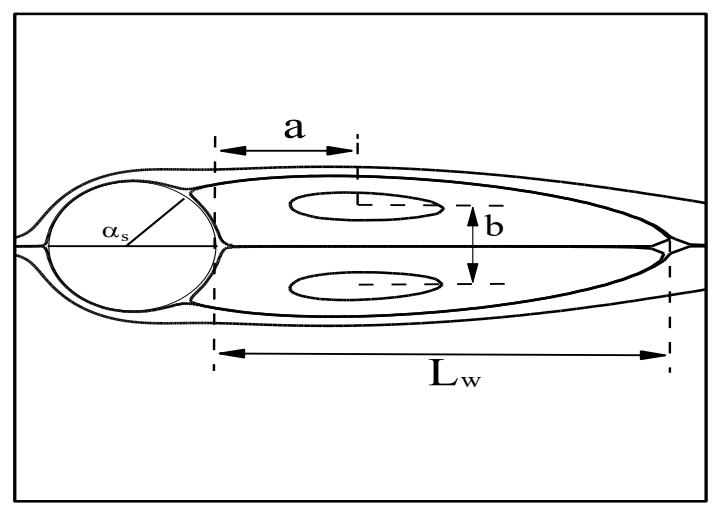

Fig. 2. Wake bubble geometry. 
developed in order to take into account the boundary layer problem. The methodology of the solution was validated by comparing the drag coefficient, the connecting length and the separation angle for $R e=40$. The study of the mesh showed that the variation of the parameters calculated between the M2 mesh and the meshM3 is weak, which allows us to take the M2 mesh for the rest of the study.

\subsection{Validation of Results}

The solution has been validated by comparing in Table 2, drag coefficient, angle of separation and length of reattachment for $R e=40$, which is the largest value in the range considered for simulation. Values obtained in current simulation are found to match closely with data number for the solid volume fractions is shown in Fig. 3. This figure shows that the wave length is linearly increased by any increase in Reynolds number for both nanofluid and clear fluid. However, the slope of this increment increases any increase in solid volume fraction. Flow separation occurs when the streamlines no longer remain attached to the body and causes wakes near the surface. Angular position of the separation point is a function of Reynolds number. The separation angle past the cylinder $(\alpha)$ is presented versus Reynolds number for different solid volume fractions in Fig. 4. The separation angle is measured from the front stagnation point $(\alpha=0)$. It is evident in this figure that the separation point shifts towards the front stagnation point $(\alpha=0)$ as $\varphi$ increases. The flow field will experience separation only if the

Table 2

Validation of present work results with literature values for $R e=40$

\begin{tabular}{|l|l|c|c|c|c|c|}
\hline & \multicolumn{1}{|c|}{ Authors } & $\boldsymbol{C D}_{\boldsymbol{D}}$ & $\boldsymbol{\alpha}_{\boldsymbol{s}}$ & $\frac{L w}{D}$ & $\frac{a}{D}$ & $\frac{b}{D}$ \\
\hline Exp. & Coutanc. \& Bouard[28] & -- & 126.2 & 2.13 & 0.76 & 0.59 \\
\hline & Taira \& Colonius [30] & 1.54 & 126.3 & 2.30 & 0.73 & 0.60 \\
\hline Numerical & Linnick \& Fasel [27] & 1.54 & 126.4 & 2.28 & 0.72 & 0.60 \\
\hline & Rémi Gautier et al. [31] & 1.49 & 126.4 & 2.24 & 0.71 & 0.51 \\
\hline Study & Bouchon et al.[32] & 1.50 & 126.6 & 2.26 & 0.71 & 0.60 \\
\hline & Pres. Work & 1.50 & 126.3 & 2.25 & 0.71 & 0.61 \\
\hline
\end{tabular}

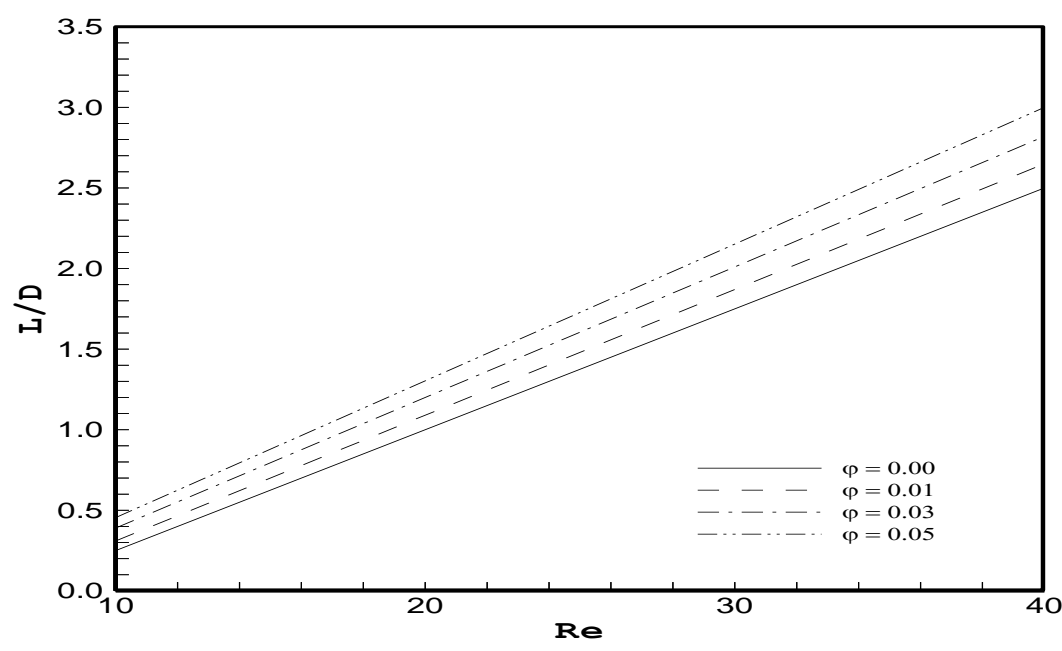

Fig.3.Variation of wake length with Re at different solid volume fractions $\varphi$.

published in literature.

\section{Results and discussion}

Below this Reynolds number, the flow is characterized by the presence of a symmetric pair of closed separation bubbles. Beyond $\mathrm{Re}=40$, the flow becomes unsteady and asymmetric, and alternate vortex shedding begins. The reattachment length of the wake is measured from the downstream side of the cylinder to the point where the velocity changes sign from negative to positive. The comparison between the ratio of the wave length to the cylinder's diameter L/D versus Reynolds inertial forces are of sufficient magnitude. In nanofluid, inertial forces in the flow field increases. Hence, separation is moved towards front stagnation point comparing with clear fluid. The separation angle $(\alpha)$ is decreased by increasing in Reynolds number for both nanofluid and clear fluid.

The magnetic field effects on the overall flow pattern are depicted in Fig. 5. The figure shows the streamlines for various Hartmann numbers and at $R e=40$. The Lorentz force in magnetohydrodynamics actually acts as a damping force that suppresses any instability in the flow structure. Experimentally, it has been established those two-dimensional instabilities can be suppressed by the application of the external magnetic field. The flow 


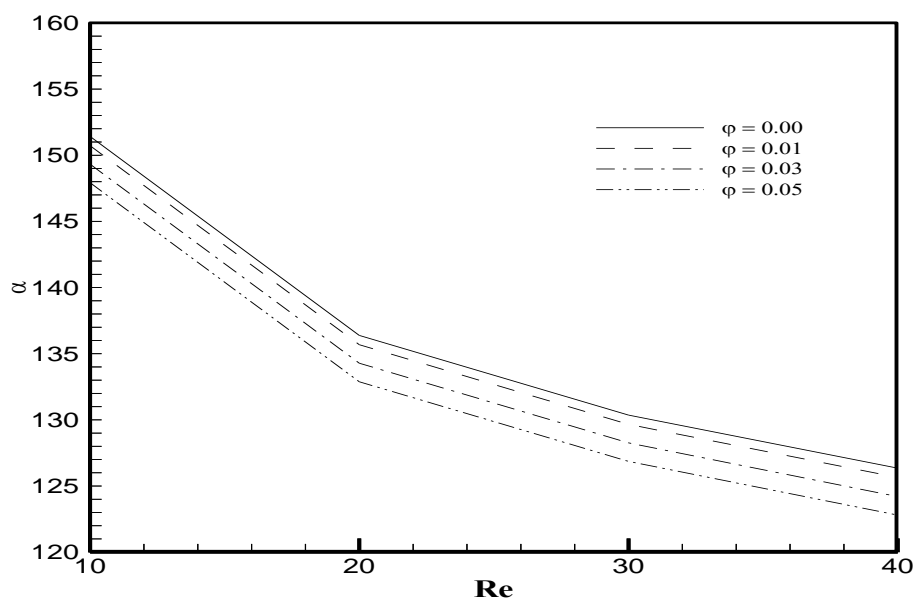

Fig.4. Variation of separation angle with $R e$ at different solid volume fractions $\varphi(\mathrm{Ha}=0)$.

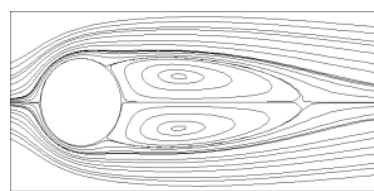

$$
H a=0
$$
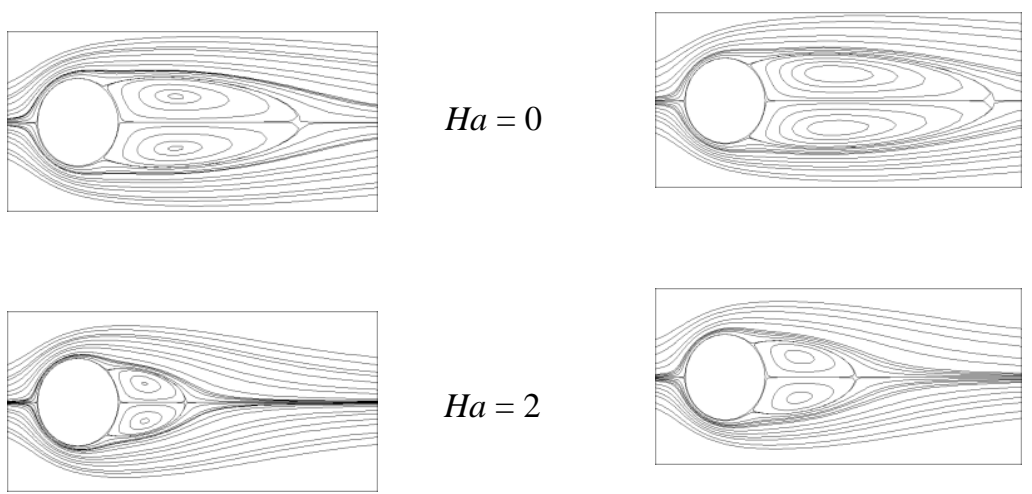

$$
H a=2
$$
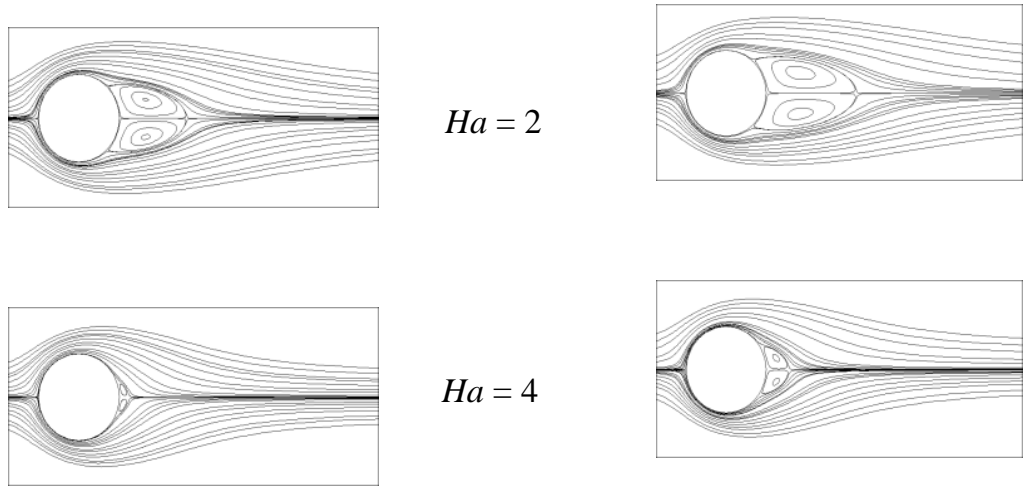

$H a=4$
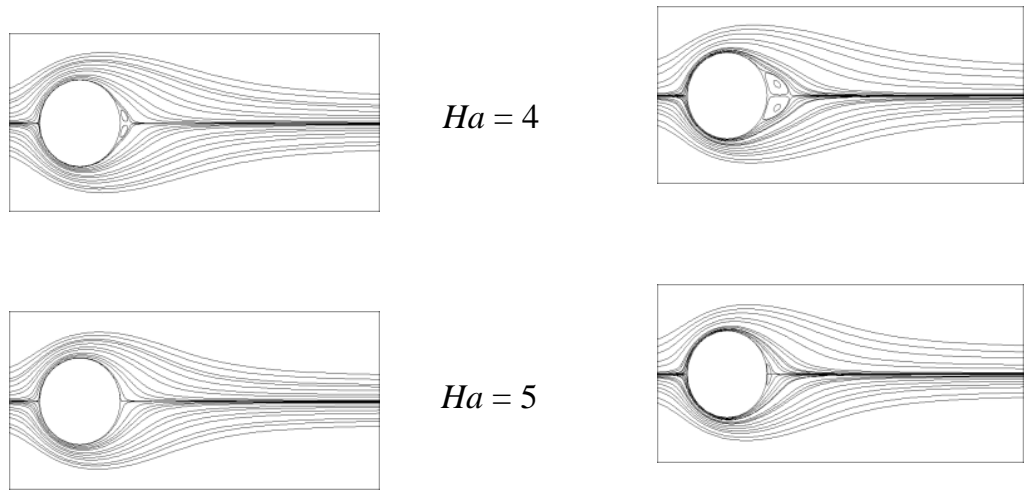

$H a=5$
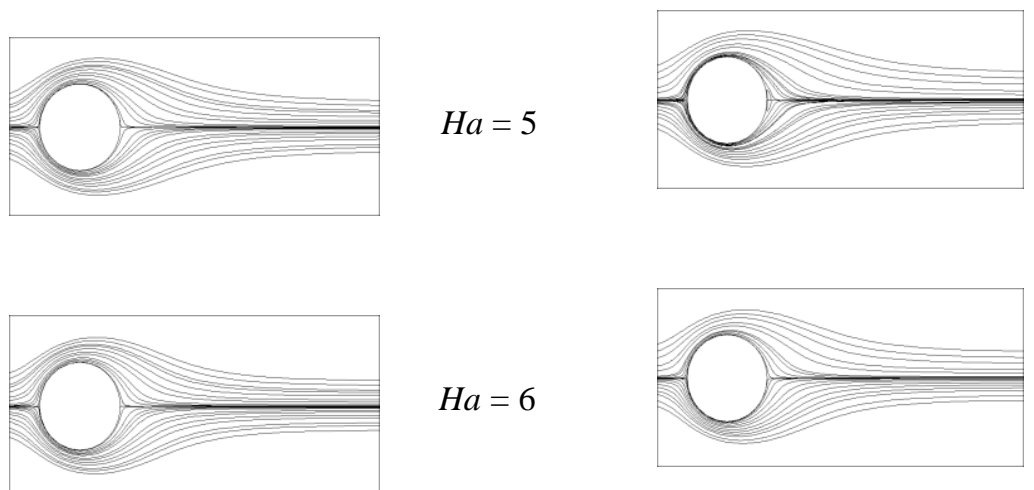

$H a=6$

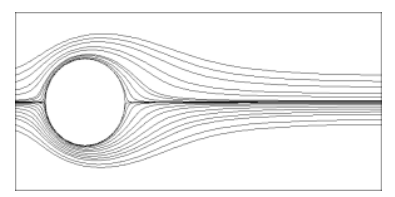

Fig.5. Streamlines for $R e=40$ at different Hartmann numbers for $\varphi=0 \%$ (left) and $\varphi=5 \%$ (right).

separation at the rear stagnation point can be suppressed by the magnetic field applied perpendicular to the cylinder surface. Looking at the streamline patterns in Fig. 4, the preceding fact of the suppression of the wake region is strongly established.

The recirculation region progressively diminishes, both longitudinally and laterally, with the increase in the magnetic field strength. At some critical value of the magnetic field strength the flow does not separate at all 
behind the obstacles and, above the critical field strength, the flow creeps over the surface of the cylinders. We call this critical value of the magnetic field strength for which a steady separated flow is completely suppressed and becomes a creeping flow type the critical Hartmann number (the minimum Hartmann number required for complete suppression).

Figure 6 shows the variation of the critical Hartmann number responsible for the suppression of the steady wake bubble with the Reynolds number for the clear and nanofluid. The minimum Hartmann number requirement for flow suppression increases with the Reynolds number and the clear fluid requires a stronger magnetic field strength for suppression, compared to its nanofluid counterpart. Since the flow instability increases with an increasing Reynolds number due to a larger inertia effect, a stronger magnetic field is required to suppress the hydrodynamic instability. The hydrodynamic instability, once again, is more intensified due to the presence of the nanoparticles in comparison to the clear fluid and a stronger magnetic field is required for flow suppression.

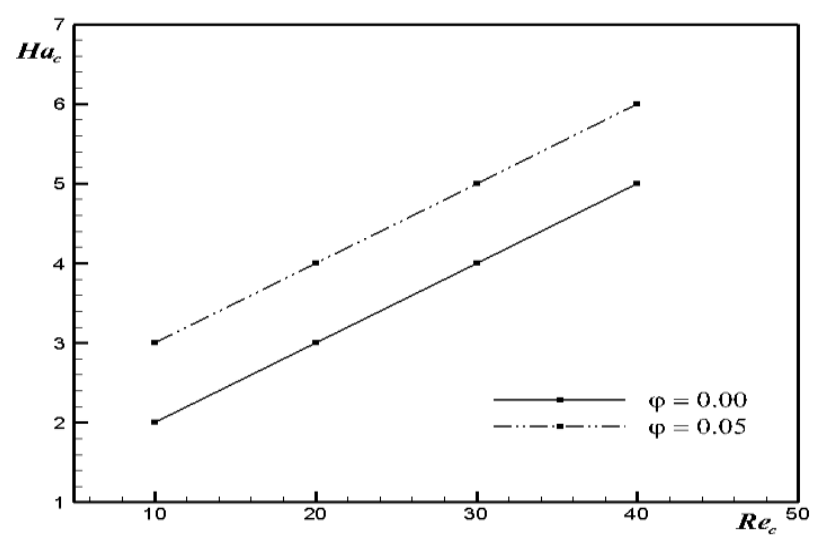

Fig.6. Critical Hartmann number as a function of Reynolds number for $\varphi=0 \%$ and $\varphi=5 \%$.

In this section, we investigated the effect of nanoparticle volume fraction on heat transfer performance of nanofluid. The quantification of heat transfer is characterized by local and average Nusselt number. The Nusselt number is a function of various factors such as heat capacitance and thermal conductivity of both the base fluid and the nanoparticles, the volume fraction of suspended particles, the viscosity of the nanofluid as well as the wake structure.

The local Nusselt number of the nanofluid based on cylinder diameter is defined as:

$$
N u=-\left[\frac{k_{n f}}{k_{f}} \frac{\partial T}{\partial n}\right]_{\text {alongthecylindersurface }}
$$

Surface averaged Nusselt number of fully developed thermal boundary layer is defined as:

$$
N u_{\text {ave }}=\frac{1}{s} \int_{s} N u d s
$$

Variation of surface average Nusselt number with
Hartmann number at $R e=40$, for the clear and nanofluid is shown in Figure 7.

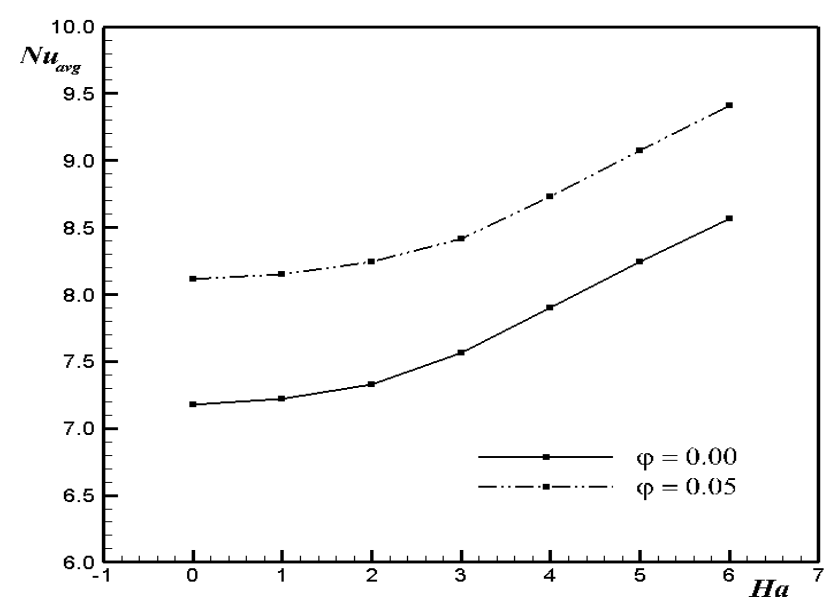

Fig 7. Variation of surface average Nusselt number with Hartmann number for $\operatorname{Re}=40(\varphi=0 \%$ and $\varphi=5 \%)$.

In this figure it is shown that increasing both $\mathrm{Ha}$ and solid volume fraction will increase the average Nusselt number. One of the main reasons for this behavior is:

- the motion of nanoparticles that transport heat energy;

- the micro-convection of fluid surrounding nanoparticles;

- since the wake region decreases at a faster rate for the transversely applied magnetic field, the Nusselt number increases with magnetic field strength.

Variation of local Nusselt number on the surface of cylinder versus $\alpha$ at different solid volume fractions is shown in Fig. 8. This figure indicates that any increase in the solid concentration improves the effective thermal conductivity and consequently the rate of heat transfer. Also, thermal boundary layer is decreased by any increase in solid volume fraction. Therefore, the local Nusselt number is enhanced by any increasing in solid volume fraction. As it is shown in this figure, the maximum value of Nusselt number is in the vicinity of front stagnation point $(\alpha=0)$. However, it decreases gradually along with the wall of cylinder up to a minimum value closed to the point of separation.

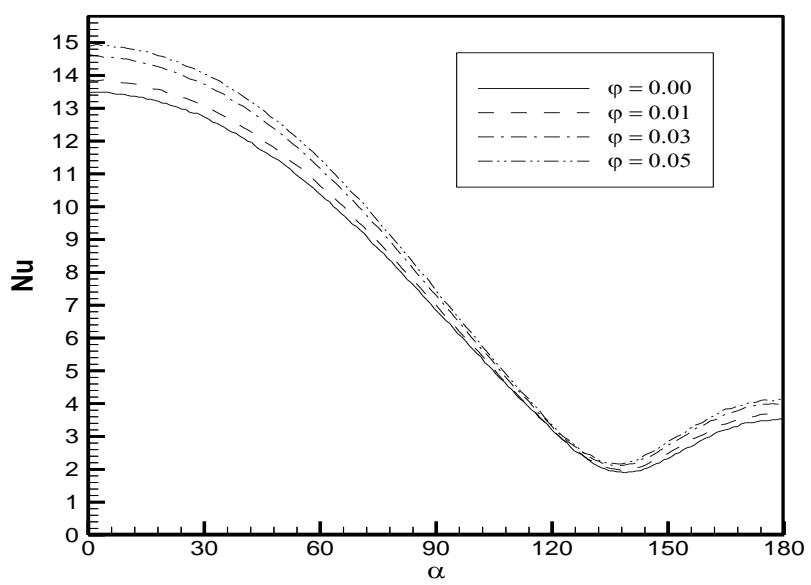

Fig. 8.Variation of local Nusselt number on cylinder. 


\section{Conclusions}

Numerical simulation is carried out to analyze the hydrodynamic and thermal transport phenomena for flow of an electrically conducting fluid over a circular obstacle in a two dimensional unconfined medium. The magnetic field is imposed transverse directions. The simulations are performed for Re range of (10 - 40) and Hartman number (0 - 6) considering nanofluid as the working fluid.

From this study, we could draw the following conclusions:

- Higher solid volume fraction of nanoparticles in a base fluid improves its thermo physical properties considerably. The outcome of such modification is higher Nusselt number or better heat transfer rate.

- Higher solid volume fraction accelerates the fluid as is seen from Stream function analysis. So there is therefore more wall shear stress developed.

- Basically, when the fluid flows due to convection in presence of any magnetic field, it causes Lorentz force in the fluid which reduces the velocity of the fluid particles.

- The imposed transverse magnetic field effectively suppresses the hydrodynamic instability; because of the faster decay of wake region (bubble length and width).

- Increasing strength of external magnetic field has a positive impact on heat transfer process and relation between $\mathrm{Ha}$ and $\mathrm{Nu}$ is completely reciprocal,

- Stronger magnetic field creates a force field that acts against the fluid flow. This interaction results in increase in local and average $\mathrm{Nu}$. Stronger external magnetic field thus has impact on both flow and thermal fields as can be seen from streamline and Nusselt number plots.

Khelili Y. - Doctor of Mechanical Engineering Department of Energy Mechanics and Fluids.

Bouakkaz R. - Doctor of Mechanical Engineering Department of Energy Mechanics and Fluids.

[1] R. D. Selvakumar, S. Dhinakaran, J. Mol. Liq. 223,572 (2016); https://doi.org/10.1016/j.molliq.2016.08.047.

[2] R. D Selvakumar, \& S. Dhinakaran, Intl J. Heat Mass Transfer 115, 282 (2017); https://doi.org/10.1016/j.ijheatmasstransfer.2017.07.103.

[3] Najiyah Safwa Khashi'ie, Iskandar Waini, Nurul Amira Zainal, Khairum Hamzah, and Abdul Rahman Mohd Kasim, Symmetry 12,1493 (2020); https://doi.org/10.3390/sym12091493.

[4] M.S. Valipour, R. Masoodi, S. Rashidi, M. Bovand and M. Mirhosseini, Therm. Sci.18(4),1305 (2014); https://doi.org/10.2298/TSCI121224061V.

[5] M. Vegad, S. Satadia, P. Pradip, P. C hirag, P. Bhargav, Procedia Technol. 14,348 (2014); https://doi.org/10.1016/j.protcy.2014.08.045.

[6] J.C.M. Garnett, Royal Society of London. Series A. Containing Papers of a Math. or Phy. Character 237 (1906); https://doi.org/10.1098/rsta.1906.0007.

[7] M. Sheikholeslami' Seyyed Ali Farshad, Z. Ebrahimpour, Zafar Said, A review, Journal of Cleaner Production 293,126119 (2021); https://doi.org/10.1016/j.jclepro.2021.126119.

[8] R.T.H. Bing, H.A. Mohammed, J. Purity, Util. React. Environ. 1,435 (2012).

[9] V. Etminan-Farooji, E. Ebrahimnia-Bajestan, H. Niazmand, S. Wongwises, Int. J. Heat Mass Transf. 55(5),1475 (2012); https://doi.org/10.1016/j.ijheatmasstransfer.2011.10.030.

[10] A.J. Chamkha, A.M. Rashad, A.M. Aly, Meccanica 48 (1), 71 (2013); https://doi.org/10.1007/s11012-012-9584$\underline{8})$.

[11] M. Sheikholeslami,Seyyed Ali Farshad,Zafar Said, Int. Com. in Heat and Mass Tran, 123,105190 (2021); https://doi.org/10.1016/j.icheatmasstransfer.2021.105190.

[12] S. Sarkar, S. Ganguly, G. Biswas, Int. J. Heat Mass Transf. 55(17), 4783 (2012); https://doi.org/10.1016/j.ijheatmasstransfer.2012.04.046.

[13] S. Sarkar, S. Ganguly, A. Dalal, Int. J. Heat Mass Transf. 59, $433 \quad$ (2013); https://doi.org/10.1016/j.ijheatmasstransfer.2012.12.032.

[14] S. Sarkar, S. Ganguly, A. Dalal, P. Saha, S. Chakraborty, Int. J. Heat Fluid Flow 44, 624 (2013); https://doi.org/10.1016/i.ijheatfluidflow.2013.09.004.

[15] S. Sarkar, S. Ganguly, A. Dalal, J. Heat Transf. 136(6),062501 (2014); https://doi.org/10.1115/1.4026470.

[16] Y. Kolesnikov and A. Tsinober9, 621 (1974); https://doi.org/10.1007/BF01031323.

[17] G. Mutschke, V. Shatrov and G. Gerbeth, Exper. Thermal and Fluid Science16, 92 (1998); https://doi.org/10.1016/S0894-1777(97)10007-3.

[18] M. M. Bhatti, A. Riaz and R. Ellahi, M. Sheikholeslami, Journal of Porous Media 17, 143 (2014); https://doi.org/10.1615/JPorMedia.v17.i2.50.

[19] N. Sher Akbar, M. Raza and R. Ellahi Magnetism and Magnetic Materials 381, 405 (2015); https://doi.org/10.1016/i.jmmm.2014.12.087.

[20] K. Sheikholeslami and R. Ellahi, J. of Zeitschrift Fur Naturforschung A 70,115 (2015); https://doi.org/10.1515/zna-2014-0258.

[21] H.S. Yoon, H.H. Chun, M.Y. Ha and H.G. Lee, Int. J. of Heat and Mass Transfer 47, 4075 (2004); https://doi.org/10.1016/j.ijheatmasstransfer.2004.05.015. 
[22] D. G. E. Grigoriadis, I. E. Sarris and S. C. Kassinos, Computers \& Fluids 39,345 (2010); https://doi.org/10.1016/j.compfluid.2009.09.012.

[23] D. Chatterjee and B. Mondal, Int. J. of Heat and Mass Transfer 54, 5262 (2011); https://doi.org/10.1016/j.ijheatmasstransfer.2011.08.016.

[24] W.K. Hussam, M.C. Thompson and G.J. Sheard, Int. J. of Heat and Mass Transfer 54, 1091 (2011); https://doi.org/10.1016/j.ijheatmasstransfer.2010.11.013.

[25] D. Chatterjee, K. Chatterjee, B. Mondal, Journal of Fluids Engineering 134,091102 (2012); https://doi.org/10.1115/1.4007316.

[26] Y. Khelili, A. Allali, R. Bouakkaz, Engineering Review 39, 261 (2019); https://doi.org/10.30765/er.39.3.07.

[27] M. Linnick, H. Fasel, J. Comput. Phys. 204,157 (2005); https://doi.org/10.30765/er.39.3.07.

[28] M. Coutanceauand R. Bouard, J. Fluid Mech, 79,231 (1977); https://doi.org/10.1017/S0022112077000135.

[29] Y. Khelili, A. Allali and R. Bouakkaz, Metallurgical and Materials Engineering 23, 83 (2017); https://doi.org/10.30544/242.

[30] K. Taira, T. Colonius, J. Comp. Phys. 225, 2118 (2007); https://doi.org/10.1016/j.jcp.2007.03.005.

[31] R. Gautier, D. Biau, E.Lamballais, Computers \& Fluids 75, 103 (2013); https://doi.org/10.1016/j.compfluid.2012.12.017.

[32] Bouchon, T. Dubois, N. James, Comp \& Flu. 65, 80 (2012); https://doi.org/10.1016/j.compfluid.2012.02.011.

[33] Khelili, A. Allali, R. Bouakkaz, Sudia UBB Chemia, LXIII, 1, 239 (2018); https://doi.org/10.24193/subbchem.2018.1.17.

\title{
Ясін Хелілі, Рафік Буакказ
}

\section{Вплив магнітного поля на стійкість потоку нанорідини до перешкод}

\author{
Університет Бліда, Алжир, khliliyacine1@gmail.com
}

На основі квазідвовимірної моделі чисельно досліджено потік та теплообмін нанорідини повз круговий циліндр у прямокутному каналі під сильним поперечним магнітним полем. Перехід від ламінарного потоку 3 розділенням до в'язкого ламінарного потоку визначається як функція числа Гартмана та об'ємної частки наночастинок, що є критичним числом Гартмана, і передачі тепла від нагрітої стінки до рідини. Виявлено, що змішування поперечного потоку, яке викликається циліндром, збільшує теплообмін. Послідовні зміни в структурі потоку вивчаються, як функція числа Гартмана. Затухання вихрового потоку відбувається зі збільшенням числа Гартмана.

Ключові слова: нанорідина; магнітогідродинаміка; об'ємна фракція; число Гартмана. 